\title{
SUSCETIBILIDADE A DANO PELO FRIO EM ABACAXI 'PÉROLA' TRATADO COM 1-METILCICLOPROPENO'
}

\author{
OVÍDIO RICARDO DANTAS JÚNIOR², SILVANDADE MELO SILVA ${ }^{3}$, \\ RICARDOELESBÃOALVES ${ }^{4}$, EBENÉZER DE OLIVEIRASILVA $^{4}$
}

RESUMO - Este trabalho avaliou o efeito de 1-metilciclopropeno (1-MCP) na suscetibilidade ao dano pelo frio em abacaxi 'Pérola', colhido em Santa Rita-PB, na maturidade comercial. Os frutos foram tratados com 1$\operatorname{MCP}(0 ; 300 ; 600$ e $1.200 \mathrm{ppb})$, por 12 horas, sob condição ambiente e armazenados: a) durante 42 dias a $10^{\circ} \mathrm{C}$, avaliados a cada 7 dias, e quando transferidos para o ambiente $\left(25^{\circ} \mathrm{C}\right.$ e $65 \pm 5 \%$ U.R.), após $21 ; 28 ; 35$ e 42 dias, e também foram avaliados após sete dias; b) durante 32 dias, a $7^{\circ} \mathrm{C}$, avaliados a cada 8 dias, e transferidos para o ambiente após 8; 16; 24 e 32 dias, sendo avaliados após sete dias. Em frutos mantidos a $10^{\circ} \mathrm{C}$, não se observou efeito do 1 -MCP em retardar a perda de qualidade. Para frutos a $7^{\circ} \mathrm{C}$, o 1 -MCP minimizou a incidência de dano pelo frio quando transferidos para a condição ambiente.

Termos para indexação: Ananas comosus, desordem fisiológica, 1-MCP, armazenamento refrigerado.

\section{SUSCEPTIBILITY TO CHILLING INJURY FOR 'PÉROLA’ PINEAPPLE TREATED WITH 1-METHYLCYCLOPROPENE}

\begin{abstract}
This work evaluated the effect of 1-methylcyclopropene (1-MCP) on susceptibility to chilling injury (CI) in 'Perola' pineapple, harvested at the commercial maturity from Santa Rita municipality, Paraíba State, Northeast Brazil. Fruits were treated at room temperature with 1-MCP $(0,300,600$, and $1200 \mathrm{ppb})$ for a 12-hour period and stored: a) during 42 days at $10^{\circ} \mathrm{C}$, evaluated each 7 days and, when transferred to room conditions $\left(25^{\circ} \mathrm{C}\right.$ and $65 \pm 5 \%$ R.H.), followed $21,28,35$, and 42 days, and were also evaluated after 7 days; $b$ ) during 32 days at $7{ }^{\circ} \mathrm{C}$, evaluated at 8 -day intervals, transferred to room conditions followed 8, 16, 24, and 32 days, and evaluated after 7 days. For pineapple kept at $10^{\circ} \mathrm{C}$ it was not observed 1-MCP effect of retarding the loss of fruit quality. For fruits stored at $7^{\circ} \mathrm{C}, 1-\mathrm{MCP}$ minimized the incidence of $\mathrm{CI}$ when pineapples were transferred to room conditions.
\end{abstract}

Index terms: Ananas comosus, physiological disorder, 1-MCP, cold storage.

\section{INTRODUÇÃO}

O Brasil é um dos maiores produtores mundiais de abacaxi, com uma produção estimada, no ano de 2006, em 1,7 bilhão de frutos. Em todo o País, são encontrados plantios comerciais, destacando-se os Estados do Pará, Paraíba, Minas Gerais, Bahia e Rio Grande do Norte, que contribuíram com quase $72 \%$ da produção nacional em 2006 (IBGE, 2008). A maioria do abacaxi produzido no Brasil, no entanto, é ainda destinada ao mercado doméstico, cujo transporte para outras regiões é geralmente feito a granel e sob condições ambientes (CEAGESP, 2003).

A refrigeração tem sido utilizada como um dos meios mais eficientes na redução da taxa metabólica e, consequentemente, no aumento da vida útil pós-colheita de frutos (Kays, 1997). O emprego de refrigeração pode ser a ferramenta necessária para a comercialização do abacaxi paraibano em mercados mais distantes. Cada produto, no entanto, possui uma faixa ótima de temperatura que pode potencializar a vida útil pós-colheita. Frutos tropicais e subtropicais, quando expostos a temperaturas inferiores a $10-12^{\circ} \mathrm{C}$, exibem a desordem fisiológica denominada dano pelo frio ou "chilling injury" (Lyons, 1973), que resulta em perda da qualidade e redução da vida útil pós-colheita (Wang, 1994). Quando exposto a temperaturas abaixo de $10^{\circ} \mathrm{C}$ por um tempo prolongado, o abacaxi exibe dano pelo frio (Teisson \& Combres, 1979), que decorre do efeito das baixas temperaturas nas membranas celulares

${ }^{1}$ (Trabalho 082-08). Recebido em: 02-04-2008. Aceito para publicação em: 09-12-2008.

${ }^{2}$ Aluno de Doutorado em Agronomia/Programa de Pós-Graduação em Agronomia-UFPB, ovidiojunior@yahoo.com.br ${ }^{3}$ Prof. Ph.D., Lab. Biologia e Tecnologia Pós-Colheita, DCFS/CCA/UFPB, C.P. 04, 58397-970, Areia - PB. E-mail: silvasil@cca.ufpb.br

${ }^{4}$ Pesq. Dr., Embrapa Agroindústria Tropical, R. Dra Sara Mesquita, 2270, Pici, 60511-110, Fortaleza-CE, elesbao@cnpat.embrapa.br; ebenezer@cnpat.embrapa.br 
(Wang, 1994). Os danos pelo frio manifestam-se em abacaxi na forma de vários sintomas, como amadurecimento anormal, colapso da estrutura interna, manchas escuras na polpa e na casca ou descoloração interna e perdas em sabor e odor (Paull \& Rohrback, 1995). A incidência de danos pelo frio é agravada na presença de etileno (Pesis et al., 2002). O 1-metilciclopropeno (1-MCP) é um composto eficiente no controle dos efeitos adversos do etileno (Sisler \& Serek, 1997). Rupasinghe et al. (2000) e Selvarajah et al. (2001) observaram que o emprego de 1-MCP reduziu consideravelmente a incidência de dano pelo frio em maçã e abacaxi, respectivamente. No entanto, Porat et al. (1999), em laranja 'Shamouti', um fruto não- climatérico, não verificaram efeitos de 1-MCP na redução da ocorrência de dano pelo frio.

O objetivo deste trabalho foi determinar o efeito da aplicação de 1-MCP na suscetibilidade a danos pelo frio de abacaxi 'Pérola', armazenado a 10 e $7^{\circ} \mathrm{C}$.

\section{MATERIAL E MÉTODOS}

Abacaxis da variedade 'Pérola' foram colhidos entre 6 e 9h da manhã, em plantio comercial conduzido sob o sistema de Boas Práticas Agrícolas, no município de Santa Rita- PB, no estádio de maturidade comercial (fisiologicamente maduros, porém com frutilhos de coloração verde em toda a extensão da casca), classificados como "verdoso", de acordo com as Normas de Classificação do Abacaxi (CEAGESP, 2003). Em seguida, foram transportados em caixas isotérmicas para o Laboratório de Fisiologia e Tecnologia Pós-Colheita da Embrapa Agroindústria Tropical, Fortaleza-CE, onde foram selecionados, e cada abacaxi foi pincelado na base com solução de 1 g.L $\mathrm{L}^{-1}$ de fungicida e seco ao ar. Em seguida, para o tratamento com 1Metilciclopropeno (1-MCP), os abacaxis foram colocados em câmaras plásticas de $0,186 \mathrm{~m}^{3}$. Para a aplicação do 1-MCP, foram utilizados frascos de 100 $\mathrm{mL}$ com septos nas tampas, nos quais foi adicionado o produto comercial em pó nas concentrações equivalentes a 300; 600 e 1.200 ppb de 1-MCP gasoso. Em seguida, foram injetados, através dos septos, 50 $\mathrm{mL}$ de água a $50^{\circ} \mathrm{C}$, agitando-se até a completa dissolução do produto. Os frascos foram colocados no interior das câmaras contendo os abacaxis através de abertura lateral e abertos. As câmaras, em seguida, foram hermeticamente fechadas, permanecendo sob condição ambiente $\left(25 \pm 3{ }^{\circ} \mathrm{C}\right.$ e $65 \pm 5 \%$ UR) por 12 horas. Como controle, abacaxis sem aplicação de 1MCP foram mantidos em condições similares. Após a aplicação de 1-MCP, os frutos foram submetidos a dois ensaios: Ensaio I. Abacaxis armazenados a $10 \pm 1^{\circ} \mathrm{C}$ e $93 \pm 2 \%$ de umidade relativa (UR) por 42 dias, com avaliação a cada sete dias $(0 ; 7 ; 14 ; 21 ; 28$; 35 e 42 dias), sendo que, a partir do $21^{\circ}$ dia, em cada avaliação, um grupo de três frutos era transferido para a condição ambiente, que eram avaliados após sete dias, aos $21+7,28+7,35+7$ e $42+7$ dias. Ensaio II. Frutos armazenados a $7 \pm 1^{\circ} \mathrm{C}$ e $93 \pm 2 \%$ UR durante 32 dias, com avaliação a cada oito dias $(0 ; 8 ; 16 ; 24$ e 32 dias), sendo que, em cada avaliação, um grupo de três abacaxis era transferido para a condição ambiente, com avaliação após sete dias, aos $8+7$, $16+7,28+7$ e $32+7$ dias

Avaliações: Perda de Massa (\%) determinada em balança semianalítica (marca BEL, modelo Mark 3.100), considerando-se a diferença entre a massa inicial do fruto e a obtida a cada de avaliação (Martins et al., 2003); Coloração da casca, Aspecto da Coroa, Coloração da polpa e Escurecimento Interno - através de avaliação sensorial por doze julgadores não treinados, utilizando-se de escalas subjetivas, variando de 0 a 5, considerando-se 4=limite de aceitação, adaptadas de Pólit (2001). Coloração da casca: $0=$ frutilhos totalmente verdes; $1=$ centro dos frutilhos amarelos em mais de $50 \%$ do fruto; $2=$ centro dos frutilhos amarelos em $100 \%$ do fruto; $3=$ mais de $50 \%$ dos frutilhos amarelos; $4=100 \%$ dos frutilhos amarelos, mas com região entre os frutilhos verde; $5=$ totalmente amarela. Aspecto da coroa: $0=$ fresca, limpa e inteira; $1=$ ligeiramente menos túrgida, com pontas das folhas dobradas; $2=$ pequenas manchas marrons, ligeiramente murchas e secas; $3=$ manchas marrons e escuras, moderadamente torcidas e secas; 4=folhas muito marrons, folhas rotas; $5=$ com fungos, folhas rotas ou desprendidas. Coloração da polpa: $0=$ totalmente branca e sem brilho; $1=$ branca, mas ligeiramente brilhante; $2=$ ligeiramente amarela; $3=$ amarelo-pálida; 4= amarelo moderado brilhante; $5=$ amarelo intenso. Escurecimento Interno (EI): $0=0 \%$ de EI; $1=$ até $5 \%$ de EI; $2=6$ a $10 \%$ de EI; $3=11$ a $20 \%$ de EI; 4=21 a 40\% de EI; 5=41 a 100\% de EI. Dano pelo frio - avaliado nos frutos armazenados a $7^{\circ} \mathrm{C}$, após sete dias da transferência para a condição ambiente, calculado através da porcentagem de área da casca afetada por maturação irregular, conforme Paull \& Rohrbach (1985); Firmeza da Casca - usandose o texturômetro digital Stable Micro Systems, modelo TA.XT2i, com sonda de $35 \mathrm{~mm}$ de diâmetro, em duas medições, em regiões opostas ao longo da área mediana do fruto, ajustada para uma distância de penetração de $10 \mathrm{~mm}$, à velocidade de $1,0 \mathrm{~mm} \cdot \mathrm{s}^{-1}$, em Newtons (N). Teor de Vitamina $\mathrm{C}$ - por titulometria com solução de DFI (2,6 diclo-fenol-indofenol 0,02 
\%) até atingir coloração róseo-clara, utilizando-se de $1 \mathrm{~g}$ de suco diluído em $50 \mathrm{~mL}$ de ácido oxálico 0,5 $\%$, de acordo com Instituto Adolfo Lutz (2005).

O delineamento experimental foi o inteiramente casualizado. Para o ensaio I, utilizouse esquema fatorial $4 \times 7$ (4 doses de 1 -MCP x 7 tempos) para frutos mantidos a $10{ }^{\circ} \mathrm{C}$ e após a transferência para a condição ambiente, fatorial $4 \times 4$ (4 doses de 1-MCP x 4 tempos). Para o ensaio II, utilizou-se esquema fatorial $4 \times 5$ (4 doses de 1-MCP x 5 tempos) para frutos mantidos a $7{ }^{\circ} \mathrm{C}$ e após a transferência para a condição ambiente, fatorial $4 \times 4$ (4 doses de 1-MCP x 4 tempos), com três repetições de um fruto. Para os frutos que permaneceram sob refrigeração, os resultados foram submetidos à análise de variância e quando verificada a significância da interação pelo teste "F", a pelo menos $5 \%$ de probabilidade, submetidos à regressão polinomial. Para os frutos que foram transferidos para a condição ambiente, utilizou-se de contrastes ortogonais, comparando-se os valores obtidos em cada período sob refrigeração aos valores obtidos após sete dias de permanência sob condições ambientes e as doses de 1-MCP.

\section{RESULTADOS E DISCUSSÃO}

Perda de massa. A perda de massa não foi influenciada pelas doses de 1-MCP durante o período de refrigeração $(\mathrm{p}<0,05)$, sendo as diferenças decorrentes do tempo de armazenamento (Figuras $1 \mathrm{~A} \mathrm{e} \mathrm{C}$ ). A perda de massa aumentou de forma linear nos frutos mantidos sob refrigeração ininterrupta. Nos abacaxis mantidos a $7^{\circ} \mathrm{C}$, observou-se maior perda de massa durante o armazenamento (Figura 1C). Quando os frutos mantidos a 7 e $10^{\circ} \mathrm{C}$ foram transferidos para o ambiente, observou-se aumento mais acentuado na perda de massa (Figura 1B e D), provavelmente em decorrência do aumento brusco da atividade metabólica, devido a danos sofridos pelas membranas (Wang, 1994). Adicionalmente, a transferência dos frutos da refrigeração para o ambiente acelerou a perda de massa, em consequência do déficit de pressão de vapor, o qual representa a diferença entre a umidade dos tecidos do produto e a umidade do ar circundante, que, por sua vez, é afetada pela temperatura de armazenamento (Grierson \& Wardowski, 1978). A perda excessiva de massa torna o fruto inadequado para a comercialização. Dependendo do produto, perdas iguais ou superiores a $5 \%$ são capazes de promover o enrugamento, limitando a aceitação do produto pelo consumidor (Kays, 1997). A perda de massa para abacaxis tratados com 600 e $1.200 \mathrm{ppb}$ de1-MCP, mantidos por 16 dias a $7^{\circ} \mathrm{C}$, não diferiu após sete dias na condição ambiente $(16+7$ dias), o que pode ser devido à ação do 1-MCP na redução da taxa metabólica, resultando em menor taxa de transpiração e, consequentemente, em menor perda de massa.

Firmeza da casca. Para os frutos mantidos a 7 e $10^{\circ} \mathrm{C}$, a firmeza da casca diminuiu durante o armazenamento, mas não diferiu quanto às doses de 1-MCP. Entretanto, quando da transferência após 32 dias a $7{ }^{\circ} \mathrm{C}$ para a condição ambiente $(32+7)$, a firmeza de frutos não- tratados era inferior à dos frutos tratados (Figura 1D). Para a maioria dos frutos, a avanço da maturação é acompanhado pela perda de firmeza, e a sua manutenção é um dos objetivos da conservação pós-colheita (Kays, 1997). A retenção da firmeza está relacionada à integridade dos polímeros da parede celular, que são desintegrados durante a maturação pela ação de enzimas hidrolíticas, resultando no amaciamento da textura do fruto (Bartley \& Knee, 1982).

Coloração da casca. Em abacaxi, a coloração da casca é um indicativo do ponto de colheita e da maturidade de consumo (Carvalho, 1999). Esta deve apresentar a uniformidade e intensidade características, pois é o principal atrativo ao consumidor (Dull, 1971). O tratamento com 1-MCP não proporcionou diferença no desenvolvimento da coloração dos frutos mantidos sob refrigeração (Figura 2A e C). Para os frutos armazenados a $7^{\circ} \mathrm{C}$ (Figura 2C), não se observou o desenvolvimento da coloração/desverdecimento da casca, até o $32^{\circ}$ dia (nota 0 da escala). Quando da transferência, após 8; 16 e 32 dias a $7{ }^{\circ} \mathrm{C}$ para a condição ambiente $(8+7$, $16+7$ e $32+7$ dias), os frutos não-tratados com 1-MCP apresentaram menores notas, indicando que o desenvolvimento da coloração foi prejudicado, sugerindo que o sistema molecular envolvido na biossíntese de pigmentos foi afetado (Selvarajah et al., 2001). Por outro lado, nessa condição, o tratamento com 1-MCP propiciou a evolução da coloração (Figura 2D), indicando redução na incidência de dano pelo frio, como em morango (Jiang et al., 2001). Com o decorrer do tempo de exposição ao ambiente, a casca destes frutos começou a apresentar sintomas de dano pelo frio, que interferiam no desenvolvimento normal da coloração da casca. De acordo com Wang (1994), a partir do momento em que o produto é submetido à temperatura abaixo do nível crítico por prolongado período, o dano das membranas celulares é eminente, mas a velocidade de ocorrência dos sintomas é variável, dependendo 
da temperatura, tempo de exposição e estado fisiológico e metabólico do tecido.

Aspecto da coroa. A coroa proporciona proteção ao fruto nas etapas de acondicionamento e transporte, constitui-se também em material de propagação, além de representar, para o consumidor, a integridade dos frutos (Pólit, 2001). Não foram verificadas diferenças no aspecto da coroa entre os tratamentos empregados $(\mathrm{p}<0,05)$, onde apenas $\mathrm{o}$ tempo de armazenamento exerceu influência (Figura $2 \mathrm{~A} \mathrm{e} \mathrm{C}$ ). $\mathrm{O}$ aspecto da coroa evoluiu da nota 0 (coroa fresca, limpa e inteira) até a nota 2 (folhas verdes com pequenas manchas marrons, ligeiramente murchas e secas), durante o armazenamento a $10{ }^{\circ} \mathrm{C}$. Para frutos mantidos a $10{ }^{\circ} \mathrm{C}$ e transferidos para a condição ambiente, após 42 dias de refrigeração $(42+7$ dias), foi atingida nota superior a 3 (folhas com manchas marrons e manchas escuras, moderadamente torcidas e secas), o que se justifica pela própria estrutura da coroa, que é constituída por material coreáceo e recoberto de cera. Abacaxis mantidos a $7^{\circ} \mathrm{C}$, quando transferidos para a condição ambiente, tinham o aspecto da coroa mais comprometido na medida em que seu tempo de permanência sob refrigeração foi maior $(32+7)$, chegando a atingir valores superiores a 3,5 .

Coloração da polpa. $\mathrm{O}$ desenvolvimento da coloração da polpa foi pequeno, de modo que, sob as duas condições de refrigeração (Figura 3A e C), não foi alcançada sequer a nota 2 . A coloração da polpa, no entanto, evoluiu quando os frutos mantidos a $10^{\circ} \mathrm{C}$ foram transferidos para a condição ambiente, os quais alcançaram nota superior a 2 (Figura 3B). Abacaxis mantidos a $7^{\circ} \mathrm{C}$ e transferidos para condição ambiente apresentaram desenvolvimento da coloração da polpa mais discreto (Figura 3D), que corresponderia à tonalidade ligeiramente amarela, podendo indicar anormalidade no processo de amadurecimento. Esse limitado desenvolvimento da coloração da polpa observado durante a transferência para a condição ambiente pode ser decorrente da própria característica da cultivar Pérola, que é classificada como de polpa branca (Dull, 1971) e amarelo-pálida a quase branca (Carvalho, 1999). A coloração da polpa serve como indicativo do grau de maturação do fruto e é bastante influenciada pela nutrição mineral (Carvalho, 1999). De acordo com Pólit (2000), um abacaxi verde tem polpa de cor branca e muitos espaços livres em seu interior. À medida que a maturação avança, estes vazios começam a encher-se de suco, e a polpa tornase paulatinamente de cor amarela e com aparência de translúcida pela maior presença de líquido.
Escurecimento interno. Um dos principais problemas apresentados pelo abacaxi, durante e após o armazenamento ou transporte, é o distúrbio fisiológico causado pela exposição a baixas temperaturas, que é denominado de escurecimento interno, afetando a qualidade pós-colheita do abacaxi para exportação (Carvalho, 1999). Para as doses e as condições de refrigeração empregadas, não foi verificado influência do tratamento com 1-MCP $(\mathrm{p}<0,05)$ no grau de escurecimento interno dos frutos (Figura 3A e C), embora abacaxis mantidos a $10{ }^{\circ} \mathrm{C}$ mantivessem os frutos com $0 \%$ de área afetada até o $28^{\circ}$ dia de armazenamento. No entanto, o escurecimento interno aumentou marcadamente após a transferência para a condição ambiente (Figura 3B e D). Observou-se que, à medida que aumentou o tempo de exposição a $7{ }^{\circ} \mathrm{C}$, aumentou a porcentagem de área afetada pelo escurecimento interno, mas que este aumento foi menor para doses mais elevadas de 1-MCP, de modo que a concentração de $1.200 \mathrm{ppb}$ foi mais efetiva em minimizar este distúrbio (Figura 3D). Teisson \& Combres (1979) e Paull \& Rohrbach (1985) salientam que os sintomas de escurecimento interno se caracterizam pelo aparecimento de pequenas manchas escuras no ponto de inserção dos frutilhos, ao longo do cilindro central, que corresponde a uma degradação do tecido, revelada pelo aumento de translucidez, como observado neste trabalho. As partes afetadas estendiam-se progressivamente ao longo do cilindro central, de modo que, em estágios mais avançados do dano fisiológico, invadiam toda a polpa do fruto. A sensibilidade dos frutos de abacaxi ao escurecimento interno, entretanto, está estritamente ligada à composição do fruto e, em particular, ao teor de ácido ascórbico (Teisson \& Combres, 1979), cujos níveis têm sido associados com a intensidade dos sintomas deste distúrbio (Paull \& Rohrbach, 1985).

Vitamina C. As doses de 1-MCP não exerceram influência sobre o teor de vitamina $\mathrm{C}$ nos frutos $(p<0,05)$, para as duas condições de refrigeração (Figura $4 \mathrm{~A}$ e C). Para os frutos mantidos a $10^{\circ} \mathrm{C}$, o teor de vitamina $\mathrm{C}$ que, no início do armazenamento, era próximo a $65 \mathrm{mg} / 100 \mathrm{~g}$, teve um pequeno acréscimo até o sétimo dia e, a partir daí, declinou, como tende a ocorrer durante a maturação em muitos frutos (Seymour et al., 1993), atingindo ao final do armazenamento teor médio em torno de $40 \mathrm{mg} / 100 \mathrm{~g}$. A $7^{\circ} \mathrm{C}$, quando transferidos para a condição ambiente, aos $32+7$ dias, abacaxis apresentavam teores de vitamina $\mathrm{C}$ mais baixos.

Dano pelo frio. $\mathrm{O}$ dano pelo frio foi avaliado na casca pela porcentagem de maturação irregular, 
que foi bastante expressiva nos frutos mantidos a $7^{\circ} \mathrm{C}$ quando transferidos para a condição ambiente. Embora a exposição a baixas temperaturas possa expressar proteínas de choque térmico que protegem as membranas contra os danos pelo frio (Sabehat et al., 1998), em abacaxi, à medida que o tempo de exposição aumentou, aumentou também a área afetada pelo dano, onde os frutos tratados com 1MCP apresentam menor área afetada nos três últimos tempos de transferência (Figura 4). O dano pelo frio nos frutos foi evidenciado por manchas escuras com 'aspecto de queimado', as quais aumentaram com o tempo de exposição ao frio. A maturação de frutos que sofreram dano pelo frio foi lenta, irregular e incompleta. As áreas afetadas não apresentaram a cor típica da casca, reduzindo a resistência fitopatológica dos tecidos, facilitando a invasão por agentes patogênicos e seu apodrecimento, conforme também descrito por Wang (1984). Conforme Levitt (1980), a ocorrência dos sintomas de dano pelo frio depende tanto da temperatura, quanto do tempo de exposição a esta temperatura. Os sintomas iniciais aparecem quando os frutos estão ainda na temperatura adversa e acentuam-se rapidamente após sua transferência a temperaturas superiores (Wang, 1994)
A

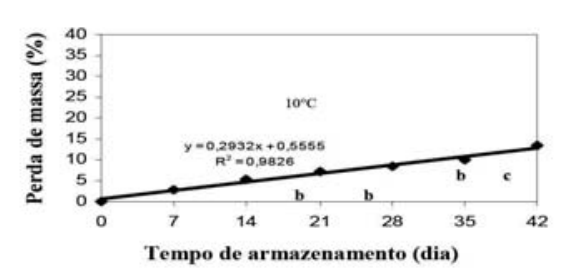

C

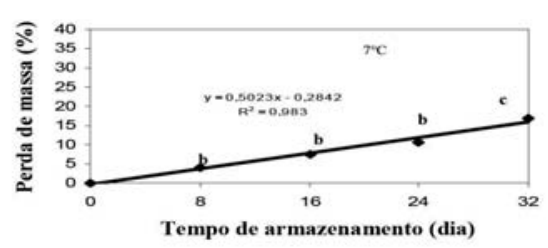

A
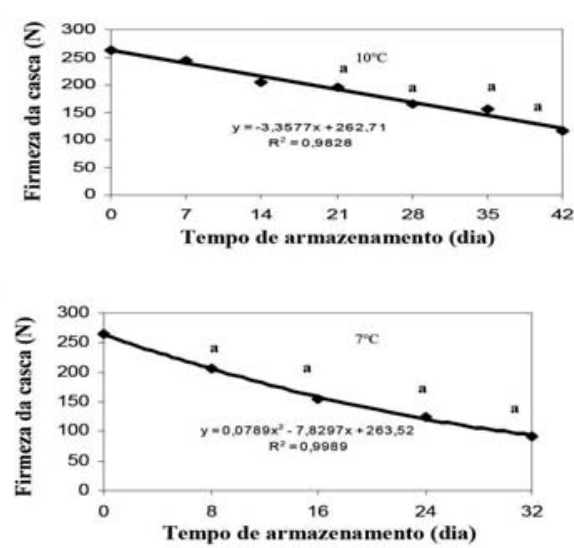

B
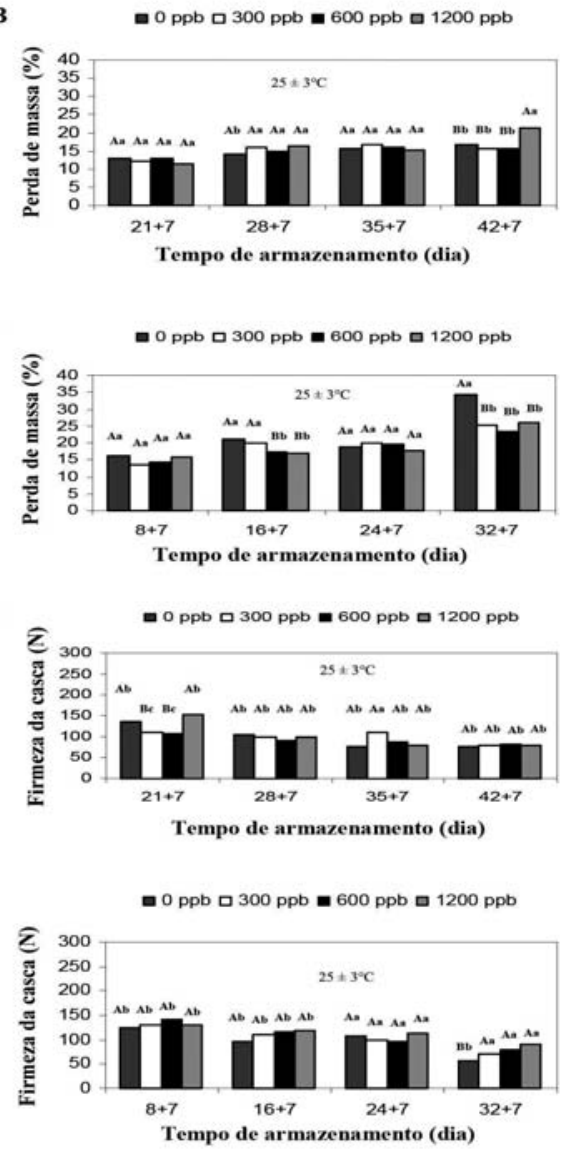

FIGURA 1- Perda de massa e firmeza da casca em abacaxi 'Pérola', tratado com 1-MCP ( 0 ; $300 ; 600$ e $1.200 \mathrm{ppb}$ ) armazenado continuadamente a $10^{\circ} \mathrm{C}$ e $93 \pm 2 \%$ U.R (A) durante 42 dias; sendo (B) a partir de 21 dias sob refrigeração (aos 21; 28; 35 e 42 dias) transferido para a condição ambiente $\left(25 \pm 3{ }^{\circ} \mathrm{C}\right.$ e $65 \pm 5 \%$ U.R.) e avaliado após sete dias nesta condição; e (C) armazenado continuadamente a $7^{\circ} \mathrm{C}$ e $93 \pm 2 \%$ U.R.durante 32 dias e (D) a partir de 8 dias sob refrigeração (aos 8; 16; 24 e 32 dias) transferido para condição ambiente e avaliado após sete dias.

*Medias seguidas das mesmas letras maiúsculas não diferem entre doses de 1-MCP e minúsculas não diferem entre a condição inicial e a de após transferência para a condição ambiente, pelo teste de Tukey, a $5 \%$ de probabilidade. 
A
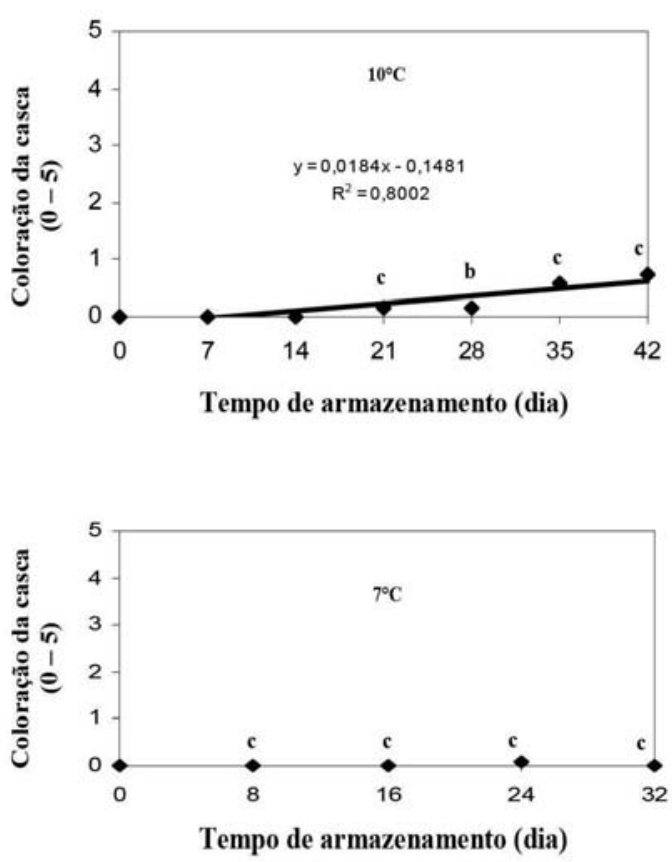

A

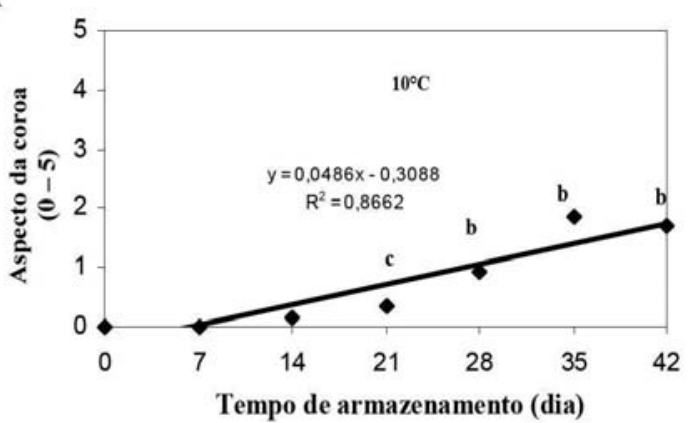

C

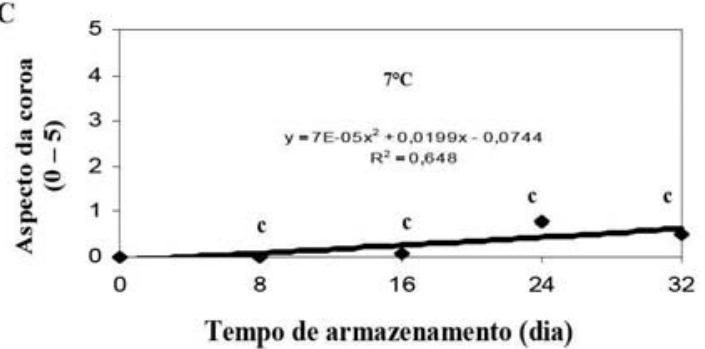

B
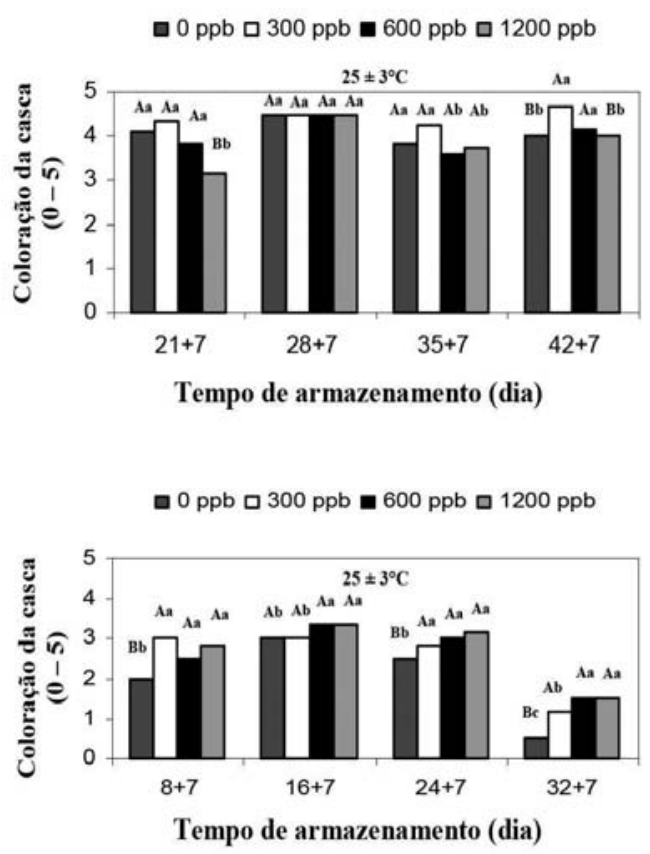

B

\ $0 \mathrm{ppb} \square 300 \mathrm{ppb} \backsim 600 \mathrm{ppb} \square 1200 \mathrm{ppb}$

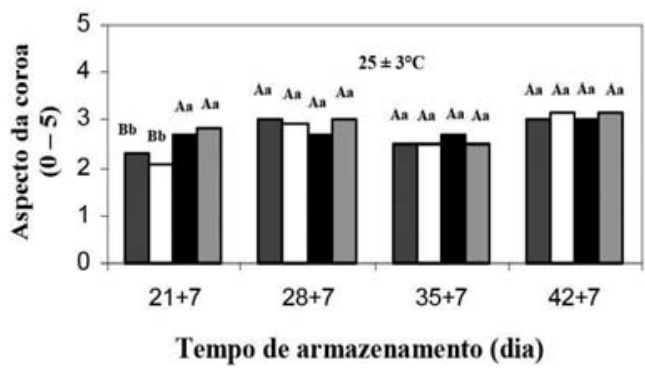

D

๑ 0 ppb $\square 300 \mathrm{ppb}=600 \mathrm{ppb}$ 口 $1200 \mathrm{ppb}$

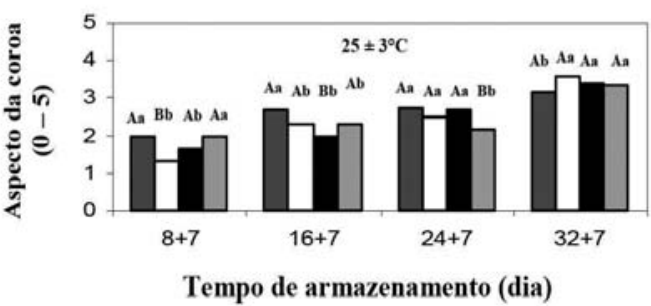

FIGURA 2- Coloração da casca (Notas de 0 - 5) e aspecto da coroa (Notas de 0 - 5) em abacaxi 'Pérola', tratado com 1-MCP $(0 ; 300 ; 600$ e $1.200 \mathrm{ppb})$ armazenado continuadamente a $10^{\circ} \mathrm{Ce} 93 \pm 2 \%$ U.R (A) durante 42 dias; sendo (B) a partir de 21dias sob refrigeração (aos 21; 28; 35 e 42 dias) transferido para a condição ambiente $\left(25 \pm 3{ }^{\circ} \mathrm{C}\right.$ e $65 \pm 5 \%$ U.R.) e avaliado após sete dias nesta condição; e (C) armazenado continuadamente a $7{ }^{\circ} \mathrm{C}$ e $93 \pm 2 \%$ U.R.durante 32 dias e (D) a partir de 8 dias sob refrigeração (aos 8; 16; 24 e 32 dias) transferido para condição ambiente e avaliado após sete dias.

*Medias seguidas das mesmas letras maiúsculas não diferem entre doses de 1-MCP e minúsculas não diferem entre a condição inicial e a de após transferência para a condição ambiente, pelo teste de Tukey, a 5\% de probabilidade. 
A

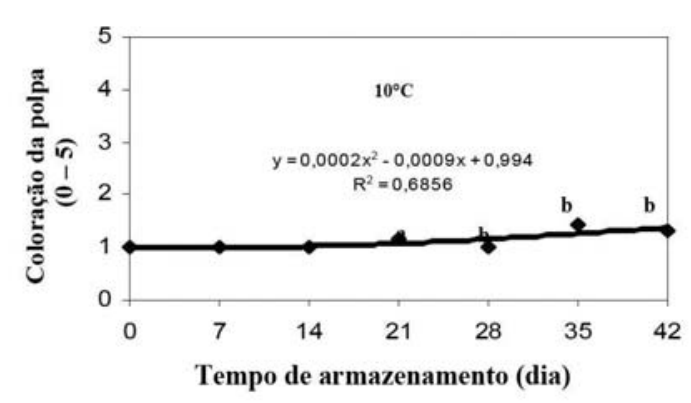

C

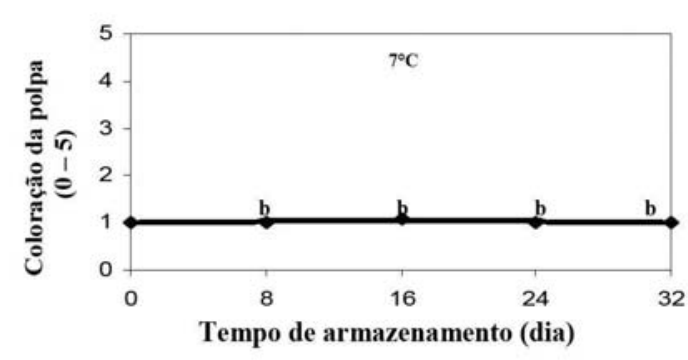

$\mathbf{A}$

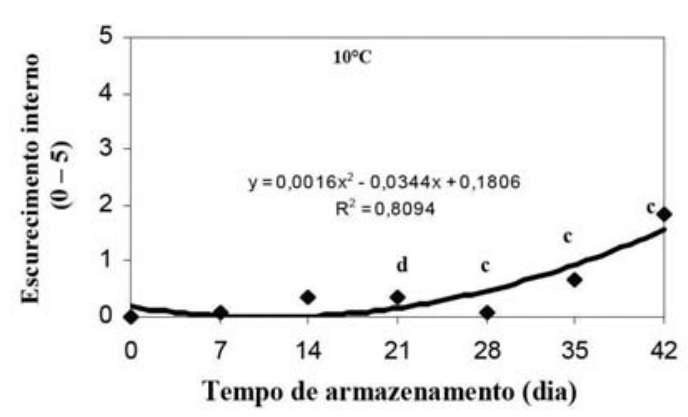

C

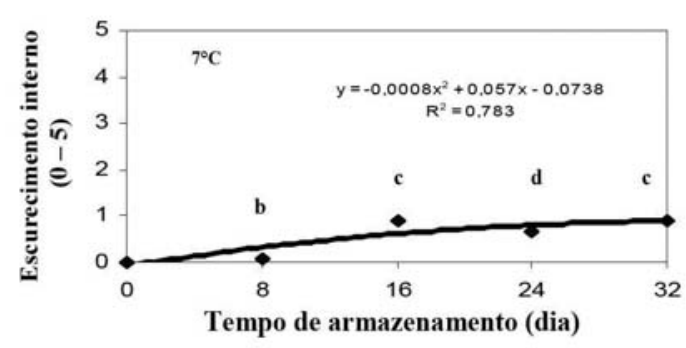

B

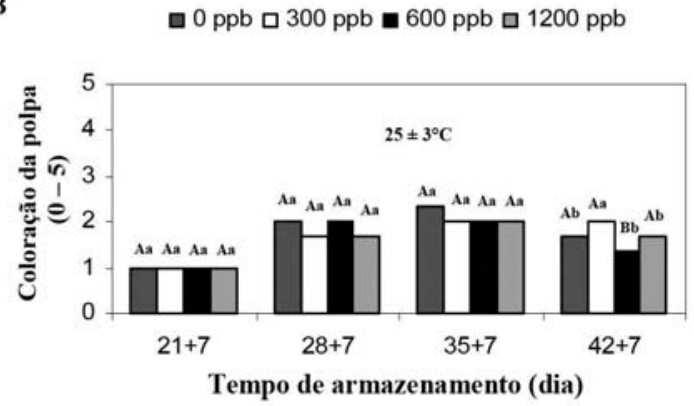

D

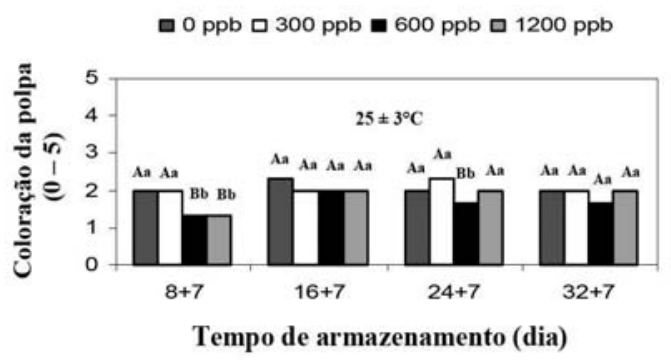

B

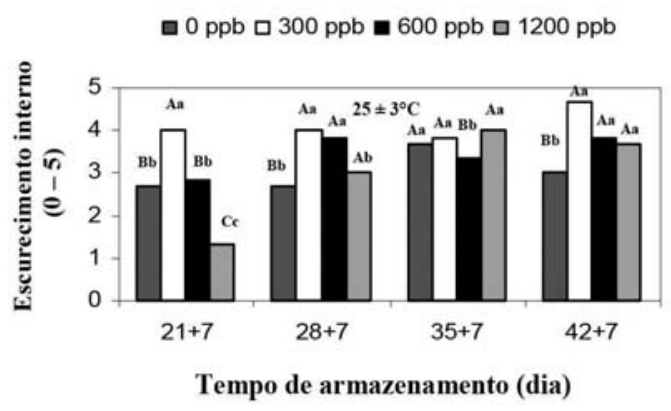

D

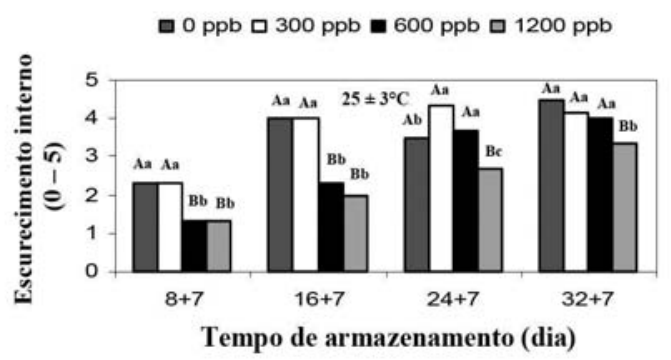

FIGURA 3- Coloração da polpa (Notas 0 - 5) e escurecimento interno (Notas 0 - 5) em abacaxi 'Pérola', tratado com 1-MCP $(0 ; 300 ; 600$ e $1.200 \mathrm{ppb})$ armazenado continuadamente a $10{ }^{\circ} \mathrm{C}$ e $93 \pm 2 \%$ U.R (A) durante 42 dias; sendo (B) a partir de 21dias sob refrigeração (aos 21; 28; 35 e 42 dias) transferido para a condição ambiente $\left(25 \pm 3^{\circ} \mathrm{C}\right.$ e $65 \pm 5 \%$ U.R.) e avaliado após sete dias nesta condição; e (C) armazenado continuadamente a $7{ }^{\circ} \mathrm{C}$ e $93 \pm 2 \%$ U.R.durante 32 dias e (D) a partir de 8 dias sob refrigeração (aos $8 ; 16 ; 24$ e 32 dias) foi transferido para condição ambiente e avaliado após sete dias.

*Medias seguidas das mesmas letras maiúsculas não diferem entre doses de 1-MCP e minúsculas não diferem entre temperaturas iniciais de armazenamento, pelo teste de Tukey, a 5\% de probabilidade. 

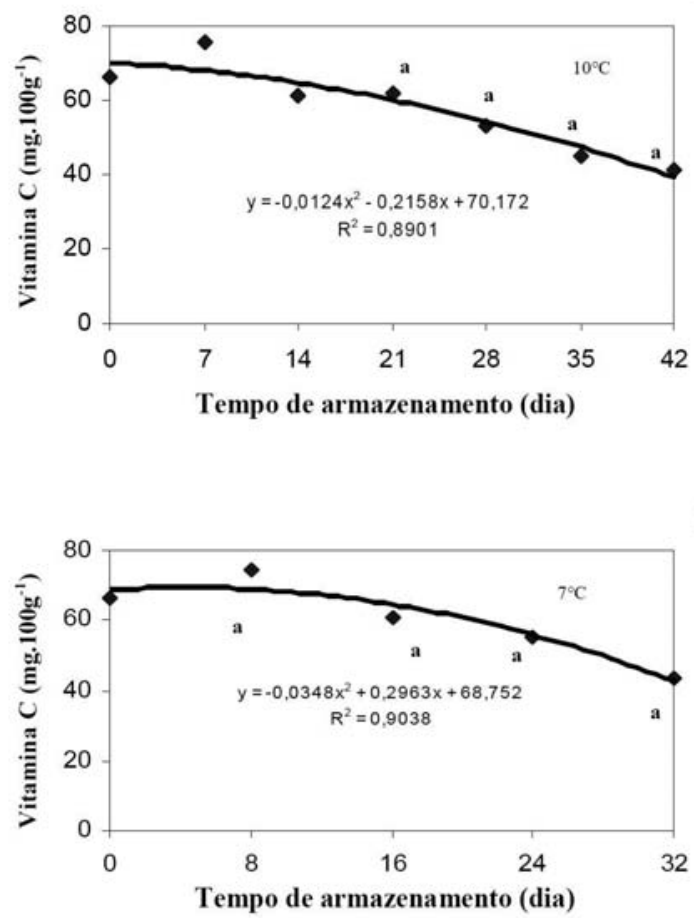

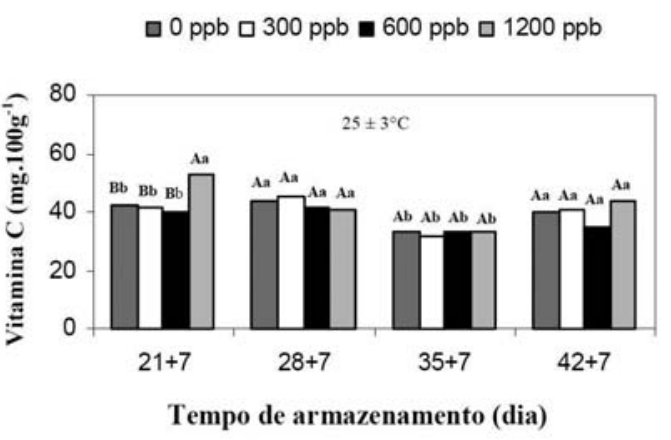

D

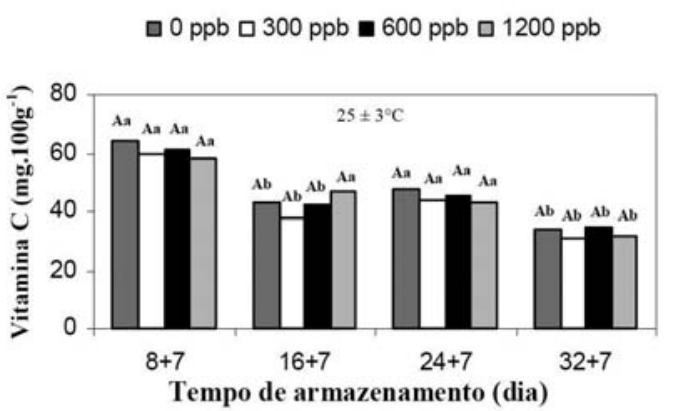

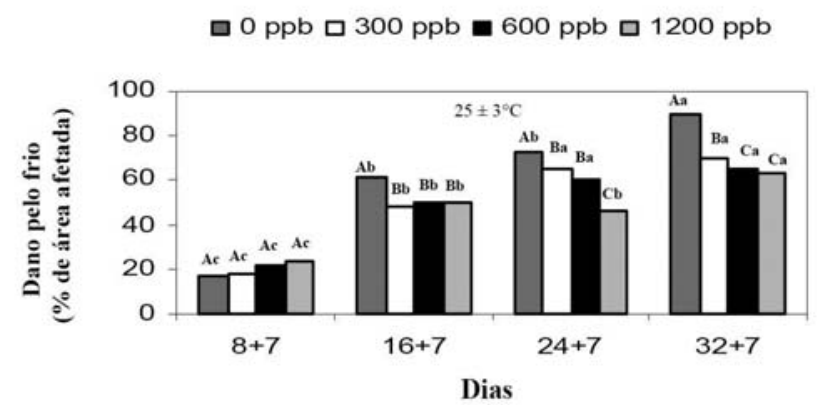

FIGURA 4- Teor de vitamina $\mathrm{C}\left(\mathrm{mg} .100 \mathrm{~g}^{-1}\right)$ em abacaxi 'Pérola', tratado pós-colheita com 1-MCP $(0 ; 300 ; 600$ e $1.200 \mathrm{ppb}$ ) armazenados continuadamente $\mathrm{a} 10^{\circ} \mathrm{C}(\mathrm{A})$; e (B) a partir de 21 dias sob refrigeração foram avaliados após sete dias de manutenção em condição ambiente $\left(25 \pm 3^{\circ} \mathrm{C}\right.$ e $65 \pm 5 \%$ U.R.); e armazenados continuadamente a $7^{\circ} \mathrm{C}$ e $93 \pm 2 \%$ U.R. durante 32 dias (C), e avaliados após sete dias sob condição ambiente (D), e Dano pelo frio (\% de amadurecimento irregular) em abacaxi 'Pérola', tratado pós-colheita de $1-\mathrm{MCP}(0 ; 300 ; 600$ e $1.200 \mathrm{ppb})$ armazenados a $7^{\circ} \mathrm{C}$ e $93 \pm 2 \%$ U.R. e avaliados após sete dias em condição ambiente.

*Medias seguidas das mesmas letras maiúsculas não diferem entre doses de 1-MCP e minúsculas não diferem entre períodos de transferência, para cada dose de 1-MCP, pelo teste de Tukey, a 5\% de probabilidade. 


\section{CONCLUSÕES}

1-O armazenamento a $7^{\circ} \mathrm{C}$ resultou na incidência de dano pelo frio em abacaxi 'Pérola'.

2-Para abacaxis mantidos a $10{ }^{\circ} \mathrm{C}$, de forma global, não se observou a efetividade do 1-MCP em retardar a perda de qualidade dos frutos.

3-Para frutos armazenados a $7{ }^{\circ} \mathrm{C}$, o 1 -MCP minimizou o escurecimento interno e a incidência de dano pelo frio quando transferidos para a condição ambiente.

\section{AGRADECIMENTOS}

Os autores agradecem ao CNPq, ao PRODETAB e ao BNB, pelo auxílio financeiro.

\section{REFERÊNCIAS}

BARTLEY, I. M.; KNEE, M. The chemistry of textural changes in fruit during storage. Food Chemistry, Oxford, v.9, n.1, p.47-58, 1982.

CARVALHO, D. C. Composição, Colheita, Embalagem e Transporte do Fruto. In: CUNHA, G. A. P. da; CABRAL, J. R. S.; SOUZA L. F. S. O abacaxizeiro: cultivo, agroindústria e economia. Brasília: Embrapa Comunicação para Transferência de Tecnologia, 1999. 480 p.

CEAGESP. Programa brasileiro para a modernização da horticultura: normas de classificação do abacaxi. São Paulo: CQH/CEAGESP, 2003. (Documentos, 24).

DULL, G. G. The pineapple: general. In: HULME, A. C. The biochemistry of fruits and their products. London: Academic Press, 1971. v.2, cap. 9, p.303324.

GRIERSON, W.; WARDOWSKI, W.F. Relative humidity effects on the postharvest life of fruits and vegetables. HortScience, Alexandria, v.13, n.5, p.2226, 1978 .

IBGE. Sistema IBGE de recuperação automática SIDRA: levantamento sistemático da produção agrícola. Disponível em: <http:// www.sidra.ibge.gov.br>. Acesso em: 12 set. 2008.

INSTITUTO ADOLFO LUTZ. Métodos físicoquímicos para análise de alimentos. 4.ed. São Paulo, 2005. 1017p.
KAYS, S.J. Postharvest physiology of perishable plant products. New York: AVI Book, 1997. 532p.

LEVITT, J. Responses of plants to enviromental stresses: chilling, freezing and high temperature stresses. $2^{\text {nd }}$ ed. New York: Academic Press, 1980. 497p.

LYONS, J.M. Chilling injury in plants. Annual Review of Plant Physiology, Palo Alto, v.24, p. 445-446, 1973.

MARTINS, L.P.;SILVA, S.M.;ALVES, R.E.; FILGUEIRAS, H.A.C. Fisiologia do dano pelo frio em ciriguela (Spondias purpurea L.). Revista Brasileira de Fruticultura, Jaboticabal, v.25,n.1,p.23-26, 2003.

PAULL, R. E.; ROHRBACH, K. G. Symptom development of chilling injury in pineapple fruit. Journal of the American Society of Horticultural Science, Alexandria, v.110, n.1, p.100-105, 1985.

PESIS,E.; ACKERMAN,M.; BEN-ARIE,R. FEYGENBERG,O.; FENG,X.; APELBAUM, A.; GOREN,R.; PRUSKY,D. Ethylene involvement in chilling injury symptoms of avocado during cold storage. Postharvest Biology and Technology, Amsterdam, v.24, p. 171-181, 2002.

PÓLIT, P. Manual de manejo postcosecha de piña. Quito: Escuela Politécnica Nacional, Graficas Guimar. 2001.28p.

PORAT, R.; WEISS, B.; COHEN, L.; DAUS, A; GOREN, R.; DROBY, S. Effects of ethylene and 1Methylcyclopene on the postharvest qualities of 'Shamouti' oranges. Postharvest Biology and Technology, Amsterdam, v.15, n.3, 155-163, 1999.

RUPASINGHE, H. P. V.; MURR, D. P.; PALIYATH, G.; SKOG, L. Inhibitory effect of 1-MCP on ripening and superficial scald development in 'McIntosh' and 'Delicious' apples. Journal of Horticultural Science and Biotechnology, Ashford, v.75, n. 3, p. 271-276, 2000.

SABEHAT, A.; LURIE, S.; WEISS, D. Expression of small heat shock proteins at low temperature. A possible role in protecting against chilling injury. Plant Physiology, Beltsville, v. 117, n.2, p. 651-658, 1998.

SELVARAJAH, S.; BAUCHOT, A. D.; JOHN, P. Internal browning in cold-storage pineapples is 
suppressed by a postharvest application of 1methycyclopropene. Postharvest Biology and Technology, Amsterdam, v.23, n.2, p.167-170, 2001.

SEYMOUR, G. B.; TAYLOR, J. E.; TUCKER, G. A. Biochemistry of fruit ripening. London: Chapman \& Hall, 1993. 454p.

SISLER, E. C.; SEREK, M. Inhibitors of ethylene responses in plants at the receptor level: Recent developments. Physiologia Plantarum, Copenhague, v.100, p.577-582, 1997.

TEISSON, C.; COMBRES, J. C. Le brumissement interne de l'ananas. III - Symptomatologie. Fruits, Paris, v.34, n.5, p.315-329, 1979.

WANG, C. Y. Chilling injury of tropical horticultural commodities. HortScience, Alexandria, v.29, n.9, p.986-988, 1994. 